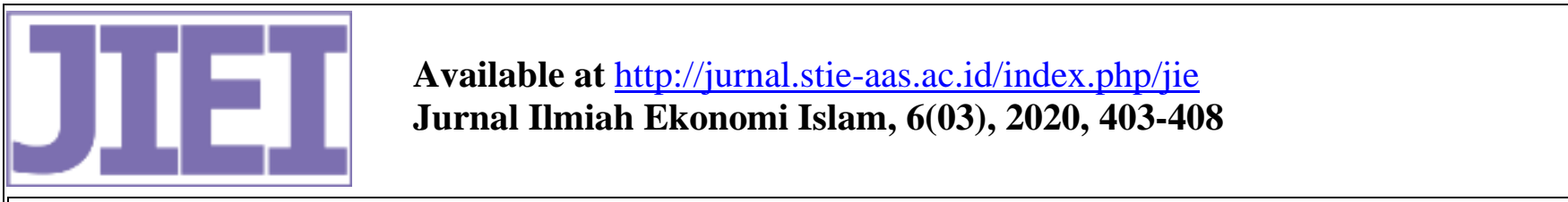

\title{
Nadzir dalam Perspektif Kelembagaan Wakaf di Indonesia
}

\author{
Agung Abdullah \\ Fakultas Ekonomi dan Bisnis Islam, IAIN Surakarta \\ *Email korespondensi : agungabd@gmail.com
}

\begin{abstract}
The contribution of waqf as an instrument of Islamic philanthropy is seen as important in providing social benefits in meeting the long-term needs of the ummah. The contribution of waqf cannot be separated from the existence of nadzir as a waqf manager. The existence of nadzir (waqf manager) is seen as the responsibility of the party responsible for the productivity of waqf assets previously not included in the terms and laws of traditional waqf in Indonesia. The purpose of this study was to analyze the existence and existence of nadzir in the perspective of waqf institutions in Indonesia. This research uses descriptive analytical method, using secondary data obtained from existing manuscript sources, one of the waqf laws. The data analysis in this study is based on a framework of four levels of institutional economy. The findings in this study are the institutionalization process of nadzir as an official institution in waqf management being analyzed using the four level of institutional economic, the first level I the institutionalization process for waqf managers in Indonesia based on customary law and then Islamic law. The second level formal institutional rules place the law as the formal management rule for waqf after the formation of the Republic of Indonesia. The third Level institutions related to waqf institutional governance that experienced improvements after the issuance of formal rules accompanied by guidance from the waqf accounting standards and the waqf core principles. Fourth Level of institutions related to the management of waqf resources in Indonesia provides wide opportunities for nadzir (waqf managers) to manage waqf. The role of the government in private waqf managers in Indonesia is as protector and issuer of regulations that support waqf productivity.
\end{abstract}

Keywords : Wakaf, Nadzir, Ekononomika Kelembagaan

Saran Sitasi: Abdullah, A. (2020). Nadzir dalam Perspektif Kelembagaan Wakaf di Indonesia. Jurnal Ilmiah Ekonomi Islam, 6(03), 403-408. doi: http://dx.doi.org/10.29040/jiei.v6i3.1216

DOI: http://dx.doi.org/10.29040/jiei.v6i3.1216

\section{PENDAHULUAN}

Di antara instrumen ekonomi Islam selain zakat, infak, dan sedekah adalah wakaf. Wakaf merupakan salah satu instrumen penting untuk pemberdayaan umat (Chizacka, 2000). Selain itu wakaf juga menjadi instrumen keagamaan dan sosial yang telah memainkan peranan penting dalam sejarah kehidupan masyarakat muslim (Dumper, 1997). Konsistensi peran wakaf telah diuji dan mampu bertahan lebih dari ribuan tahun. Dengan durasi eksistensi wakaf yang sudah sangat lama, peran wakaf sebagai penyedia keperluan untuk kepentingan umat dirasa sangat diperlukan. Berdasarkan fungsinya, harta benda wakaf menghasilkan manfaat yang mengandung unsur kebajikan kepada sesama makluk di dunia (birr), kebaikan antarumat manusia (ihsan) dan persaudaraan sesama muslim (ukhuwah Islamiyah) (Crecelius, 1995).

Lembaga pengelola wakaf sebagai lembaga swasta (sektor ketiga/lembaga non-profit) yang selama ini telah berdiri tanpa campur tangan pemerintah sebagai adat tradisi Islam, dalam perjalanannya senantiasa perlu mendapatkan dukungan dari pemerintah dalam bentuk legalitas dan perlindungan hukum. Peran pemerintah ini jauh sebelumnya telah dilakukan oleh pemerintah Mesir baik ketika masih bersistem khilafah, kemudian monarki hingga republik. Kemudian pada tahun 2004 disusul oleh Pemerintah Indonesia untuk pemberdayaan wakaf dengan menerbitkan UU Nomor 41 Tahun 2004 tentang wakaf, dengan menyebutkan bahwa pengelolaan dan pengembangan harta benda 
wakaf sebagaimana dimaksudkan pada ayat (1) dilakukan secara produktif. Yang dimaksud produktif di sini sesuai dengan penjelasan UU tersebut adalah pengelolaan dan pengembangan harta benda wakaf secara produktif dilakukan dengan berbagai cara, baik pengumpulan aset, investasi, produksi, kemitraan, perdagangan, agrobisnis, pertambangan, perindustrian, pengembangan teknologi, pembangunan gedung, apartemen, rumah susun, pasar swalayan, pertokoan, perkantoran, sarana pendidikan, sarana kesehatan, dan usaha-usaha yang tidak bertentangan dengan syariah (Departemen Agama, 2007).

Sebagai instrumen ekonomi Islam dalam bidang filantropi, wakaf telah dikenal dan diimplementasikan sejak awal kehadiran agama tersebut. Pada tahuntahun berikutnya, lembaga wakaf telah menjadi salah satu pendukung kegiatan umat Islam, terutama di bidang agama, sosial dan pendidikan. Pentingnya pendidikan termaktub dalam tujuan ke 4 yang tercantum dalam Sustainable Development Goals, yaitu untuk memastikan pendidikan berkualitas inklusif dan adil dan pembelajaran peluang hidup untuk semua manusia (UNEP, 2015). Sejalan dengan kerangka kerja $S D G s$, di antara negara-negara mayoritas Muslim, wakaf merupakan skema baru dalam pembangunan pendekatan maqasid al-syariah (tujuan yang lebih tinggi dari syariah) (Abdullah, 2018). Harapan besar dari pengelolaan wakaf produktif adalah dapat berkontribusi secara ekonomi pada lembaga pendidikan dengan cakupan yang lebih luas, seperti dalam bentuk pendanaan operasional lembaga, penyediaan beasiswa, kesejahteraan guru dan dosen. Kontribusi pengelolaan wakaf produktif terhadap kemandirian lembaga pendidikan telah terbukti baik di luar negeri ataupun dalam negeri Indonesia.

Untuk memproduktifkan wakaf maka tidak lepas dari peran penting pengelola wakaf (nadzir) dalam mengembangkan wakaf agar dapat memberikan dampak yang positif terhadap masyarakat dan negara. Nadzir wakaf dalam selayaknya manajer perusahaan yang harus mampu membuat perencanaan dan pengelolaan asset wakaf. penelitian ini lebih fokus pada proses institusionalisasi nadzir dalam pengelolaan wakaf dan bukan semata-mata pada aspek-aspek pengelolaan wakaf itu sendiri. Penelitian ini akan menggunakan teori-teori ekonomi kelembagaan baru yang semakin popular dalam beberapa dekade terakhir, khususnya teori-teori tentang empat tingkat kelembagaan (Williamson 2000) dan kerangka analisis dan pengembangan kelembagaan (Ostrom 2005).

\section{Tinjauan Pustaka}

Nadzir secara etimologi berasal dari kata kerja bahasa Arab ن ن yang berarti memandang, melihat (Munawwir, 1997). Secara terminologi fikih, yang dimaksud dengan nadzir adalah orang yang diserahi kekuasaan dan kewajiban untuk mengurus dan memelihara harta wakaf (Ramli, 1996). Pengertian lain nadzir menurut istilah adalah orang atau badan yang memegang amanat untuk memelihara dan mengurus harta wakaf dengan sebaikbaiknya sesuai dengan wujud dan tujuan harta wakaf (Ali, 1988). Dapat disimpulkan bahwa nadzir adalah pengelola wakaf baik perorangan maupun badan hukum yang berfungsi untuk mendata, mengelola dan meningkatkan produktivitas harta wakaf untuk memberikan manfaat seluas-luasnya bagi penerima manfaatnya.

Meski keberadaan nadzir dalam wakaf dipandang penting, namun nadzir sendiri bukan merupakan rukun atau syarat sahnya wakaf itu sendiri, karena wakaf adalah ibadah tabarru' yang bersifat sunnah (Rofiq, 2000). Kebutuhan akan nadzir wakaf lebih dalam rangka memenuhi tujuan pengelolaan wakaf agar produktif dan memberikan manfaat lebih. Pentingnya kebutuhan nadzir sebagai pengelola wakaf juga tidak diimbangi payung hukum yang jelas menyangkut hak-hak nadzir sebagai jasa yang diberikan atas pekerjaannya. Pengelolaan wakaf saat ini dituntut produktif, akuntabel dan terpercaya, sehingga sangat dibutuhkan dukungan dalam bentuk aturan dan rujukan yang dikeluarkan oleh lembaga resmi untuk menuntun langkah pengelolaan wakaf yang professional tersebut.

Tidak banyak penelitian tentang kelembagaan wakaf di Indonesia, penelitian tentang kelembagaan wakaf oleh Dahlan (2016) menyoroti tentang kelembagaan Badan Wakaf Indonesia secara spesifik dengan pendekatan hukum normatif. Penelitian ini akan membahas Nadzir sebagai pengelola wakaf baik perorangan maupun institusi dalam perspektif ekonomi kelembagaan secara umum.

\section{METODE PENELITIAN}

Penelitian ini bersifat kualitatif, dengan sumber data sekunder penelitian-penelitian terdahulu, bukubuku, majalah resmi, ataupun dokumen pendukung 
lainnya (undang-undang wakaf di Indonesia). Teori yang digunakan dalam penelitian ini adalah kerangka ekonomi kelembagaan (New Institutional Economics) sesuai yang dimaksud dalam definisi North (1991) tentang institusi. Yaitu, batasan-batasan yang diciptakan oleh manusia (humanly devised constraints) dalam rangka penciptaan aturan dan pembentukan interaksi politik, sosial dan ekonomi. Batasan-batasan tersebut meliputi aturan-aturan formal (contohnya: peraturan pemerintah, undangundang, dan konstitusi) dan aturan-aturan informal (contohnya: norma sosial, konvensi, adat istiadat, sistem nilai) serta proses penegakannya. Analisis kelembagaan dalam laporan penelitian ini akan didasarkan pada teori-teori ekonomika kelembagaan baru, khususnya teori-teori tentang empat tingkat kelembagaan (four levels of institutions) yang diperkenalkan oleh Williamson (2000). Empat level kelembagaan yang digunakan dalam analisis, yaitu kelembagaan level I (embeddedness/keterlekatan norma/adat/kebiasaan), kelembagaan level II (lingkungan kelembagaan/regulasi formal), kelembagaan level III (governance/tata kelola), dan kelembagaan level IV (alokasi sumber daya).

\section{HASIL DAN PEMBAHASAN}

\subsection{Hasil penelitian}

Perkembangan wakaf di Indonesia telah ada sejak sebelum zaman kemerdekaan serta sejak sebelum adanya aturan tentang wakaf yang menjadi pijakan kelembagaan formal wakaf ada. Wakaf dimasa pra kemerdekaan disebut dengan wakaf tradisional, dan banyak dipengaruhi oleh aturan adat istiadat wilayah setempat, baru kemudian setelah hadirnya agama Islam hukum fikih mendominasi aturan formal pelaksanaan dan pengelolaan wakaf. Lini masa nadzir sebagai pengelola wakaf di Indonesia yang dipengaruhi aturan nonformal hingga formal dapat dipaparkan sebagai berikut.

\begin{tabular}{|c|c|c|}
\hline Wakaf Tradisional & Menurut PP. No. 28/1977 & $\begin{array}{llllll}\text { Undang-Undang } & \text { RI } & \text { No. } & 41 & \text { Tahun } & 2004 \\
\text { Tentang Wakaf } & & & & & \end{array}$ \\
\hline 1. Wak & 1. $\mathrm{V}$ & 1. Wakif (donatur) \\
\hline 2. Tanah wakaf & 2. Tanah wakaf & 2. Nadzir (pengelola harta wakaf) \\
\hline 3. Mauquf 'alaih & 3. Mauquf alaih (peneriman & 3. Harta/benda yang diwakafkan \\
\hline (penerima & $\mathrm{m}$ & 4. Peneriman manfaaf wakaf (mauquf alaih) \\
\hline wak & 4. Shi & 5. Jangka waktu wakaf \\
\hline 4. Shigah & 5. Saksi & 6. Saksi \\
\hline wa & $\begin{array}{l}\text { 6. Pejabat Pencatat Akta Ikrar } \\
\text { Wakaf (KUA) }\end{array}$ & catat Akta Ikr \\
\hline
\end{tabular}

\subsection{Pembahasan}

Sebagaimana yang telah dipaparkan pada hasil penelitian, keberadaan nadzir sebagai pengelola wakaf dapat dianalisis pada level I kelembagaan bahwa pengelolaan wakaf tradisional oleh sekelompok orang masih berlandaskan pada aturan adat istiadat, baru kemudian aturan agama. Sebagai contoh didapati dibeberapa wilayah di Indonesia, di Banten terdapat apa yang dikenal dengan 'Huma Serang' atau berupa tanah ladang yang dikeloka bersama-sama dan setiap tahunnya mendapatkan hasil yang digunakan untuk kepentingan bersama. Daerah lain seperti di Lombok terdapat 'Tanah Pareman', atau tanah milik pemerintah setempat yang dibebaskan dari pajak tanah (landrente) yang juga dikelola bersama dan hasilnya diserahkan untuk kepentingan bersama dan membiayai operasional desa-desa di wilayah tersebut. Sementara itu di Jawa Timur terdapat 'Tanah
Perdikan', tanah ini adalah pemberian raja kepada seseorang atau kelompok yang dianggap berjasa dalam kerajaan tersebut, status tanah ini tidak boleh diperjualbelikan (Direktorat Pemberdayaan Wakaf, 2006: 13-14).

Pentingnya kedudukan nadzir dalam proses pengelolaan wakaf di Indonesia adalah sebagai lembaga yang berperan visi jangka panjang lembaga, maka dalam perkembangannya undang-undang wakaf mengamanatkan bahwa nadzir baik lembaga ataupun perseorangan harus tercantum dalam akta ikrar wakaf. Jauh sebelum disyaratkannya akta ikrar wakaf untuk penyebutan nadzir sebagai pengelola wakaf, pengelolaan wakaf bersifat informal dengan landasan hukum yang berasal dari adat-istiadat yang berbeda pada setiap wilayah. Wakaf sebelum adanya aturan tersebut kemudian disebut sebagai wakaf tradisional. Perjalanan lembaga pengelola wakaf (nadzir) sebagai 


\section{Jurnal Ilmiah Ekonomi Islam, 6(03), 2020, 406}

lembaga non-formal dalam level kelembagaan I (keterlekatan pada norma adat) dapat diuraikan ssebagai berikut :

a. Perwakafan Tanah Milik sebelum PP No. 28 Tahun 1977

Lahirnya UUPA (Undang-undang Pokok Agraria) No. 5 tahun 1960 yang merupakan unifikasi hukum tanah di seluruh Indonesia (daerah istimewa Yogyakarta baru melaksanakannya tahun 1984) memperkuat dasar hukum perwakafan, khususnya perwakafan tanah milik. Pasal 14 (1) huruf b UUPA menyatakan :

"Pemerintah dalam rangka sosialisme Indonesia, membuat suatu rencana umum mengenai peruntukan dan penggunaan bumi, air, dan ruang angkasa serta kekayaan alam yang terkandung di dalamnya :...b. untuk keperluan peribadatan dan keperluan-keperluan lainnya, sesuai dengan Ketuhanan Yang Maha Esa.”

UUPA pasal 49 menyangkut hak-hak tanah untuk peribadatan atau keperluan suci dan sosial, berbunyi:

1) Hak milik tanah badan-badan keagamaan dan sosial sepanjang dipergunakan untuk usaha dalam bidang keagamaan dan sosial diakui dan dilindungi. Badan-badan tersebut dijamin pula akan memperoleh tanah yang cukup untuk bangunan dan usahanya dalam bidang keagamaan dan sosial.

2) Untuk keperluan peribadatan dan keperluan suci lainnya sebagaimana dimaksud pasal 14 dapat diberikan tanah yang dikuasai langsung oleh negara dengan hak pakai.

3) Perwakafan tanah milik dilindungi dan diatur dengan peraturan pemerintah.

b. Perwakafan Tanah Milik setelah terbitnya PP. No. 28 Tahun 1977

Disusun berdasarakan motif konsiderannya, yaitu:

Motif keagamaan, sebagaimana tercermin dalam konsiderannya yang menyatakan bahwa "wakaf sebagai lembaga keagamaan yang sifatnya sebagai saranan keagamaan". Dalam hal ini adalah motif agama Islam. Kalau UUPA berlandaskan tujuan untuk mencapai "sosialisme Indonesia", maka PP ini bertujuan "tercapainya kesejahteraan spiritual dan material menuju masyarakat adil dan makmur berdasarkan pancasila". Dengan kata lain "sosialisme Indonesia" diartikan sesuai dengan tujuan di atas.Peraturan perwakafan, sebelumnya tidak memadai bagi penertiban hukum perwakafan secara tuntas, bahkan menimbulkan berbagai masalah, seperti tidak adanya data tentang perwakafan. Adanya landasan hukum yang kokoh, dengan diundangkannya UUPA No. 5 tahun 1960, khususnya pasal 14 [1] huruf b, dan pasal 49 [3] sebagaimana telah dijelaskan sebelumnya.

Pada level kelembagaan II (regulasi formal wakaf) keberadaan wakaf sendiri mulai diatur dalam peraturan perundangan mulai tahun 1977 yaitu menurut PP Nomor 28 tahun 1977 dan kemudian resmi dilembagakan melalui Undang-Undang RI nomor 41 tahun 2004. Sebelum adanya Badan Wakaf Indonesia sebagai dampak dari ditetapkannya UU RI No. 41 Tahun 2004 tentang wakaf, penetapan nadzir wakaf dilakukan oleh Kantor Urusan Agama pada tiap Kecamatan di bawah koordinasi Kementerian Agama RI (tahun 1977 s.d tahun 2004). Dalam UU No. 41 Tahun 2004, disebutkan bahwa nadzir sebagai pengelola wakaf dapat berupa perseorangan, organisasi, dan badan hukum. Masing-masingnya memiliki beberapa persyaratan yang harus dipenuhi. Syarat bagi nadzir perseorangan adalah berkewarganegaraan Indonesia, beragama Islam, dewasa, amanah, mampu secara jasmani dan rohani, serta tidak terhalang melakukan perbuatan hukum. Adapun syarat bagi nadzir organisasi adalah semua anggota organisasi tersebut harus memenuhi persyaratan nadzir perseorangan, dan organisasi tersebut juga harus bergerak di bidang sosial, pendidikan, kemasyarakatan, dan/atau keagamaan Islam. Adapun nadzir berbadan hukum selain harus memenuhi syarat-syarat di atas, juga harus dibentuk sesuai dengan peraturan yang berlaku. Setelah semua syarat terpenuhi, baru kemudian diadakan pengukuhan nadzir.

Pengukuhan nadzir utamanya dilakukan dalam rangka tertib administrasi pengelola wakaf dan dalam rangka memudahkan koordinasi serta pembinaan terhadap para nadzir wakaf di seluruh Indonesia. Organisasi wakaf di Indonesia selain berada dibawah Kementerian Agama, juga berada dibawah koordinasi Badan Wakaf Indonesia. Tugas Badan Wakaf Indonesia sendiri tidak mudah, selain sebagai perpanjangan tangan pemerintah RI dalam pengelolaan wakaf (nadzir), tetapi juga sebagai pengawas dan pembina perwakafan di Indonesia. Dampak dari institusionalisasi nadzir bagi lembaga wakaf ibarat memberikan tanggung jawab kemudi mobil kepada sopir, saat harta sudah diwakafkan maka nadzir yang akan mengarahkan pengelolaan harta wakaf tersebut untuk apa dan bagaimana. 


\section{Jurnal Ilmiah Ekonomi Islam, 6(03), 2020, 407}

Pada level kelembagaan III (tata kelola) menunjukan bahwa tata kelola wakaf di Indonesia mengadopsis sistem Good Corporate Governance yang awalnya digunakan dalam tata kelola perusahaan dengan mengimplementasikan asas-asas atau prinsipprinsip transparansi, akuntabilitas, tanggungjawab, kemandirian dan keadilan atau kesetaraan. Prinsipprinsip Good Corporate Governance diterapkan dalam pengelolaan wakaf menjadi Good Nadzir Governance dengan memegang asas transparansi dan akuntabilitas dimana nadzir wajib mengungkapkan pengelolaan dana wakaf secara periodik dan transparan kepada umat. Hal ini dilakukan sebagai bentuk pertanggungjawaban kepada para pemangku kepentingan sebagai pengambilan keputusan serta sebagai bentuk upaya peningkatan kepercayaan kepada masyarakat.

Akuntanbilitas dan transparansi yang ada pada lembaga wakaf dinilai akan berdampak pada semakin kuatnya legitimasi sosial, dimana lembaga itu akan mendapat public trust. Terselenggaranya akuntabilitas pengelolaan wakaf di Indonesia juga didukung oleh terbitnya Pernyataan Standar Akuntansi (PSAK) 112 tentang wakaf pada 22 Mei 2018 oleh Dewan Standar Akuntansi Syariah Ikatan Akuntansi Indonesia.

Selain pada pedoman akuntansi wakaf, di tahun yang sama (2018) pemerintah Indonesia melalui Bank Indonesia dan Badan Wakaf Indonesia bekerjasama International Research of Training Institute-Islamic Development Bank (IRTI-IsDB) meluncurkan Waqf Core Principal untuk mendukung keberhasilan pengelolaan serta pengembangan wakaf di Indonesia. Tujuan dari diterbitkannya Waqf Core Principal adalah, Pertama bertujuan untuk memberikan deskripsi ringkas tentang posisi dan peran manajemen dan sistem pengawasan wakaf dalam program pengembangan ekonomi. Kedua, untuk memberikan satu metodologi yang memuat prinsip-prinsip inti dari manajemen dan sistem pengawasan wakaf (bwi.go.id).

Tata kelola lembaga wakaf yang baik (good nadzir governance) merujuk pada Waqf Core Principal (2018) poin ke 13 dapat tercapai dengan baik karena faktor internal dan eksternal. Faktor internal fokus kepada kemampuan nadzrir itu sendiri yang dalam beberapa hal, yaitu kemampuan pemasaran, analisis bisnis dan investasi, manajemen risiko, dan kemampuan manajemen keuangan. Sedangkan faktor eksternalnya adalah dari kesadaran masyarakat untuk berwakaf. Perpaduan pengelolaan wakaf yang professional dan tingginya kesadaran masyarakat dalam berwakaf menjadi modal utama tujuan wakaf dalam memberikan kesejahteraan sosial yang lebih luas. Nadzir sebagai lembaga pengelola wakaf menjadi ujung tombak pengembangan dan pengelolaan harta wakaf dituntut untuk menjadi profesional dalam hal ini. Waqf Core Principle yang di inisiasi oleh pemerintah Indonesia hanya berfungsi sebagai pendekatan terciptanya nazhir profesional semata-mata hanyalah prinsip biasa jikalau tidak diimplementasikan dengan baik.

Pada level kelembagaan IV (alokasi sumber daya) dapat dianalisis bahwa data asset wakaf di Indonesia yang mayoritas sumber wakaf berasal dari wakaf keluarga, maka lembaga pengelola wakafnya pun mayoritas masih dikelola oleh orang yang mempunyai hubungan kekerabatan dengan wakif. Sehingga untuk pengalokasian sumber daya baik manusia maupun harta benda wakaf masih ada keterkaitan dengan wakif (orang yang mewakafkan). Hubungan kekerabatan antara wakif dan nadzir dirasa sebagai kaderisasi yang efektif dan efisien dalam rangka transformasi nilai, semangat juang, cita-cita luhur wakif kepada anak keturunannya agar harta yang diwakafkan dapat memberikan manfaat lebih luas. Namun dengan luasnya tanah wakaf dan bertambahnya obyek wakaf modern lainnya serta tidak begitu dikenalnya wakaf ahli di Indonesia menjadikan kesempatan kerja untuk para calon nadzir terbuka sangat luas (tidak hanya untuk anak keturunan wakif), baik sebagai nadzir perseorangan-organisasidan badan hukum. Dampak dari aturan kelembagaan wakaf di Indonesia memungkinkan setiap pengelola wakaf untuk berinovasi dalam pengelolaan wakaf tanpa terikat aturan pemerintah dan dapat mengalokasikan sumber daya wakafnya dengan independen.

Hubungan lembaga pengelola wakaf swasta dengan Pemerintah Indonesia adalah sebagai mitra, bukan sebagai agent-principal. Hubungan kemitraan yang sejajar antara swasta dan Pemerintah ini menjadi kekuatan lembaga wakaf untuk lebih independen, berkaca pada pengelolaan wakaf di luar negeri diantaranya harus sesuai dengan kemauan pemerintah setempat.

\section{KESIMPULAN}

Proses pelembagaan pengelolaan wakaf di Indonesia sebagai lembaga resmi dengan penggunaan 


\section{Jurnal Ilmiah Ekonomi Islam, 6(03), 2020, 408}

hukum adat kemudian hukum Islam sebagai norma yang mengatur wakaf pada tingkat pertama. Aturan formal kelembagaan pengelola wakaf baru terbit setelah terbentuknya Negara Kesatuan Republik Indonesia melalui undang-undang yang terus disempurnakan dari waktu ke waktu. Tata kelola kelembagaan wakaf semakin menunjukkan kinerja yang positif dengan adanya panduan akuntansi khusus tentang wakaf dan terbitnya Waqf Core Principle. Pengelolaan sumber daya wakaf di Indonesia dapat dilakukan secara independen oleh nadzir tanpa adanya intervensi oleh Pemerintah. Peran Pemerintah Indonesia pada pengelola wakaf swasta adalah baik sebagai pelindung dan penerbit aturan yang mendukung produktivitas wakaf. Tidak menutup kemungkinan ada peran Pemerintah di Negara lain yang sangat dominan (melakukan intervensi) kepada pengelola wakaf di wilayahnya untuk dijadikan tema lanjutan dari penelitian ini.

\section{UCAPAN TERIMA KASIH}

Penulis menyampaikan terima kasih kepada seluruh pihak yang sudah memberikan dukungan dan doa sehingga penulis dapat menyelesaikan penelitian ini.

\section{REFERENSI}

Abdullah, M. 2018. Waqf, Sustainable Development Goals (SDGs), and Maqasid al-Shariah. International Journal of Social Economics, 45(1), pp. 158-172. doi: 10.1108/IJSE-10-2016-0295.

Ali, Muhammad Daud. 1988. Sistem Ekonomi Islam; Zakat dan Wakaf. Jakarta: UI Press.

Bank Indonesia. 2018. Waqf Core Principal, pdf.

Cizakca, Murat. 2000. A History of Philantropic Foundations: The Islamic World from the Seventh Century to the Present. Economic Department Bogazici.

Crecelius, Daniel. 1995. Introduction. Journal of the economic and Social History of The Orient. Vol.38.

Dahlan, Rahmat. 2016. Analisis Kelembagaan Badan Wakaf Indonesia. Esensi : Jurnal Bisnis dan Manajemen. Jakarta, UIN Syarif Hidayatullah.
Departemen Agama Republik Indonesia. 2006. Perkembangan Pengelolaan Wakaf di Indonesia, Jakarta: Direktorat Pemberdayaan Wakaf Dirjen Bimas Islam.

Departemen Agama RI, 2007. Penjelasan atas Undang-Undang RI No. 41 Th 2004 tentang Wakaf. Dirjen Binmas.

Cahyani, D. I., \& Sumadi, S. (2015). Alternatif Sistem Ekonomi Islam Untuk Indonesia Yang Lebih Sejahtera. Jurnal Ilmiah Ekonomi Islam, 1(02).

Dumper, Michael. 1997. Wakaf Kaum Muslimin di Negara Yahudi, terj. Burhan Wirasubrata. Jakarta: Lentera.

Ikatan Akuntan Indonesia, 2018. Pernyataaan Standar Akuntansi (PSAK) 112 tentang Wakaf. Jakarta, Salemba Empat.

Munawwir, Ahmad Warson. 1997. Kamus AlMunawwir Arab-Indonesia. Surabaya: Pustaka Progresif.

Ostrom, E. (2005). Understanding institutional diversity. Princenton, New Jersey: Princenton University Press.

Ramli, Ibnu Syihab. 1996. Nihayah al-Muhtaj Juz IV. Beirut: Daar al-Kitab al Alamiyah.

Rofiq, Ahmad. 2000. Hukum Islam di Indonesia. Jakarta: PT Raja Grafindo Persada North, Douglass C. 1991. Institution. The Journal of Economic Perspectives, Vol. 5, No. 1. pp. 97112.

UNEP. 2015. Indicators and Data Mapping to Measure Sustainable Development Goals (SDGs) Targets: Case of Indonesia. Jakarta: UNDP.

Williamson, Oliver E., 2000. "The New Institutional Economics: Taking Stock, Looking Ahead". Journal of Economics Literature 38(3):595-613.

Aturan Perundang-undangan :

Peraturan Pemerintah No. 28 tahun 1977 tentang Perwakafan Tanah Milik.

Undang-Undang Nomor 5 Tahun 1960 Tentang Undang-Undang Pokok Agraria.

Undang-Undang Republik Indonesia, Nomor 41 Tahun 2004 tentang Wakaf. 